\title{
WATER INFILTRATION OF COVERING SOILS WITH DIFFERENT TEXTURES AND BULK DENSITIES IN GRAVEL- MULCHED AREAS
}

\author{
DONG, Q. G. ${ }^{1,2,3,4^{*}}-$ HAN, J. C. ${ }^{1,2,3,4^{*}}-$ ZHANG, Y. $.^{1,2,3,4}-$ LI, N. ${ }^{1}-$ LEI, N. $.^{1,2,3,4}-$ SUN, Z. H. ${ }^{1,2,3,4}$ \\ - DU, Y. C. ${ }^{1,2,3,4}-$ HE, J.1, ${ }^{1,3,4}$ \\ ${ }^{1}$ Shaanxi Provincial Land Engineering Construction Group Co., Ltd., Xi'an 710075, China \\ ${ }^{2}$ Institute of Land Engineering and Technology, Shaanxi Provincial Land Engineering \\ Construction Group Co., Ltd., Xi'an 710075, China \\ ${ }^{3}$ Key Laboratory of Degraded and Unused Land Consolidation Engineering, Ministry of \\ Natural Resources, Xi'an 710075, China \\ ${ }^{4}$ Shaanxi Provincial Land Consolidation Engineering Technology Research Center, Xi'an \\ 710075, China \\ *Corresponding author \\ e-mail:dq-guang@163.com; phone: +86-029-8862-5020
}

(Received 27 $7^{\text {th }}$ May 2019; accepted $10^{\text {th }}$ Sep 2019)

\begin{abstract}
To determine the influence of different bulk densities and texture on soil water infiltration after remediation in gravel-mulched areas, we subjected two different soil types were to a battery of tests to determine their soil infiltration characteristics. The results show that the soil infiltration capacity decreases with increasing soil bulk density. A logarithmic negative correlation was identified between stable infiltration rate and the bulk density of the two soils $\left(\mathrm{R}^{2}>95 \%\right)$. Moreover, the larger the bulk density, the smaller the cumulative infiltration, and there is a significant linear negative correlation between density and infiltration. The Kostiakov infiltration model better describes the infiltration process of the Lou soil at all stages and the infiltration of Yellow-brown soil before $40 \mathrm{~min}$. Finally, as soil water is redistributed, and its content increases with soil depth, and the greater the bulk density, the greater the water storage capacity of the soil from 0 to $30 \mathrm{~cm}$. Overall, the soil bulk density should be no less than $1.5 \mathrm{~g} / \mathrm{cm}^{3}$ when Lou soil is chosen to cover on gravel-mulched land, and not less than $1.4 \mathrm{~g} / \mathrm{cm}^{3}$ for Yellow-brown soil.
\end{abstract}

Keywords: bulk density, infiltration model, infiltration rate, cumulative infiltration, soil moisture

\section{Introduction}

Given the importance of land for development, the shortage of cultivable land resources is an important factor restricting social and economic construction in China. Bringing new land under cultivation is therefore of critical importance, and one type of reserved land that may be suitable for new cultivation are gravel-mulched areas, of which China has about $1.04 \times 10^{6} \mathrm{~km}^{2}$. Such land is widely distributed, and often possesses good light and heat conditions, thereby conferring great potential for development (Yi et al., 2013). Development of gravel-mulched areas involves constructing a new soil layer by covering the existing gravel layer. However, the soil covering process is relatively expensive, and there is a lack of corresponding theoretical research on the desired texture, density, or structure of the source soil. This is a notable limitation, since ineffective soil coverage can result in poor soil cultivation and/or inefficient water usage (Zhang et al., 2017, 2018). In order to solve 
this problem, it is necessary to further clarify the optimal bulk density of the overlying soil on the gravel-mulched areas.

Soil moisture is critical for simulating physical processes affecting soil such as surface runoff, soil erosion, and solute transport (Chen et al., 2007). Soil infiltration capacity is mainly determined by characteristics such as soil bulk density, texture and structure (Hillel, 1998; Tejedor et al., 2013). However, existing studies on the effect of bulk density on soil water infiltration focus on the differences between soil structures with single or different textures (She et al., 2012; Li Z. M. et al., 2009; Zeng et al., 2017; Sun et al., 2017). As basic physical properties of soil, changes in bulk density and pore condition cause changes in soil infiltration performance. Zeng et al. (2017) studied the effect of bulk density on water infiltration of red soil, and found that both the cumulative infiltration and infiltration rates decreased with increasing of soil bulk density. Li et al. (2009a) studied the relationship between soil water infiltration and bulk density in soils of different consistencies and reached a similar conclusion. This relationship is due to the fact that as soil bulk density increases, the aggregate structure of the soil is destroyed, decreasing porosity and making the soil tight and solid, reducing infiltration capacity (Kang et al., 2016; Wang et al., 2017). The studies about water movement in large porous media such as gravel focused on the effects of gravel cover and soil:rock ratio on soil water movement. For example, Mandal et al. (2005) and Cerdà (2001) studied water infiltration in gravel-covered soils from two sites, one in a tropical, semi-arid region of India and another in southeastern Sweden. They found that infiltration rate and humidification peak migration velocity increased with the increasing gravel cover. In addition, Zavala et al. (2010) studied the relationship between gravel coverage, runoff generation, and soil erosion in the Spanish Mediterranean coast. Novák et al. (2012) developed a simulation-based modelling approach to analyze soil water content and water transport at different soil depths, and identified the complexity of the gravel content as a major determinant of water flow. These results agreed with the findings of Zhou et al. (2009), who showed that when the gravel content is $<40 \%$, infiltration rate and hydraulic conductivity decrease with increasing gravel content, although both increase with increasing gravel content when it is $>40 \%$. Most research on the influence of gravel on soil infiltration focuses on the effect of mountain sand and/or gravel cover on water infiltration, or on moisture infiltration characteristics in mixtures of earth and stone.

However, when there is a large porous medium layer such as gravel in the lower part of the soil, a distinct layered interface is formed between the soil and gravel. Moreover, when the textures and bulk density structures of the overlying soil are different from the large-pore gravel layer, gas may be generated there. The ease of formation of water flow channels affects water movement, thereby affecting soil fertility and water retention even after gravel remediation.

Therefore, this study aimed to provide the influence of covering soil texture and bulk density on water infiltration and compare the infiltration process of two typical soils in gravel-mulched areas, which would be beneficial to determine the appropriate soil bulk density based on different soil texture in the grave-mulched land consolidation project. This information would provide a theoretical and technical basis for the development and remediation of gravel-mulched areas, and would thus facilitate to determine the reasonable bulk density of the covering soil. 


\section{Materials and methods}

\section{Test soil}

Natural soil used in experiments was collected from Lou soil deposits in Fuping County, Guanzhong, Shaanxi Province, and from Yellow-brown soil deposits in Hanzhong City, southern Shaanxi. Soil samples were collected $30 \mathrm{~cm}$ below the surface to minimize contamination by organic matter content found in the plough layer. In the actual soil-covering process, the soil is often disturbed, to ensure the same initial conditions of the experiment. Collected soil was naturally air-dried, ground, and passed through a $2 \mathrm{~mm}$ sieve. The particle composition of each stage was determined using the sedimentation method. The results of these analyses are shown in Table 1.

Table 1. Test soil particle composition

\begin{tabular}{c|c|c|c|c}
\hline Test soil type & Sand $\mathbf{( 2 - 0 . 0 5} \mathbf{~ m m})$ & Silt $(\mathbf{0 . 0 5 - 0 . 0 0 2} \mathbf{~ m m})$ & Clay $(<\mathbf{0 . 0 0 2} \mathbf{~ m m})$ & Soil texture \\
\hline Lou soil & $13.37 \%$ & $77.10 \%$ & 9.53 & Silt loam \\
Yellow-brown soil & $7.09 \%$ & $65.19 \%$ & 27.72 & Silty clay loam \\
\hline
\end{tabular}

\section{Test methods}

Next, we performed water infiltration tests to compare characteristics of infiltration. The test device has two parts: a soil column and a water supply system (Fig. 1). The soil column is a transparent plexiglass column with a diameter of $10 \mathrm{~cm}$ and a height of $50 \mathrm{~cm}, 4$ taking soil holes with a diameter of $1 \mathrm{~cm}$ are set each layer around the soil column, a total of 6 layers of soil taking holes are set to take soil for determination moisture after infiltration. The lower part of the plexiglass column contains a steel wire mesh that is highly permeable to water. The water supply (Mariotte Bottle) has the same specifications as the soil column device (i.e. a diameter of $10 \mathrm{~cm}$ and a height of $50 \mathrm{~cm}$ ), the water depth is controlled at 4-5 cm. Each test soil sample was examined at four volumetric weight levels of $1.3 \mathrm{~g} / \mathrm{cm}^{3}, 1.4 \mathrm{~g} / \mathrm{cm}^{3}$, $1.5 \mathrm{~g} / \mathrm{cm}^{3}$, and $1.6 \mathrm{~g} / \mathrm{cm}^{3}$. In order to simulate the gravel, the lower part of each test soil sample was filled with $1 \mathrm{~cm}$ diameter glass bead with the thick of $5 \mathrm{~cm}$, a layer of gauze was placed between the glass beads and the soil layer to prevent soil particle migration. Before filling, the inner wall of the pipe was coated with Vaseline. Airdried soil samples were weighed and hierarchically filled $(5 \mathrm{~cm} / \mathrm{layer})$ according to the designed bulk density. The total height of the soil was $30 \mathrm{~cm}$. A layer of filter paper was placed on the surface of the soil column to prevent the soil surface from being eroded. Infiltration measurements were made every 1-3 min at the beginning of the test, and every $5 \mathrm{~min}$ afterward until $100 \mathrm{~min}$. After this point a measurement was recorded every 10-30 min. The test was performed for $300 \mathrm{~min}$. After completion of the infiltration test, samples were taken every $5 \mathrm{~cm}$ under the surface of each soil column and the water content of each layer was determined. Samples were taken through the taking soil holes just after the $300 \mathrm{~min}$ had elapsed, as well as $1 \mathrm{~d}, 3 \mathrm{~d}$, and $10 \mathrm{~d}$ after the experiment. To eliminate the confounding influence of temperature, the indoor temperature was maintained in a range from 22 to $24{ }^{\circ} \mathrm{C}$. Each set of experiments was repeated 3 times. The regression was used to fit the measured results. 


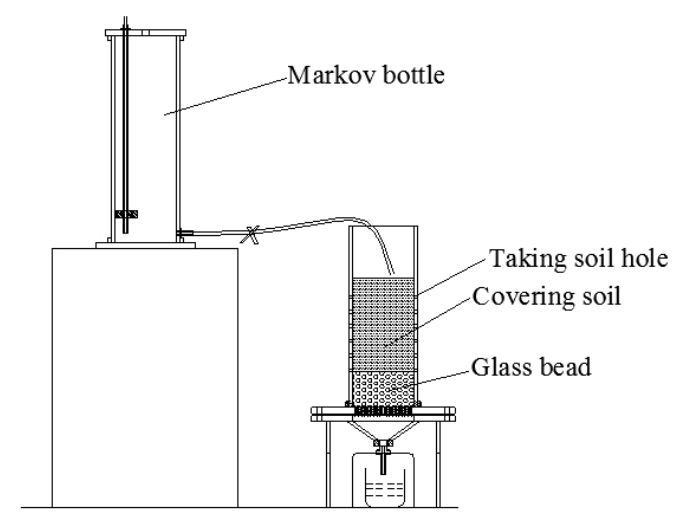

Figure 1. Schematic diagram of test device

\section{Infiltration model}

Kostiakov and Philip models were used to simulate the soil water infiltration process in gravel soil (Mehuys et al., 1975), and its applicability was evaluated. The Kostiakov model formula is:

$$
I_{t}=K \cdot t^{1-\alpha}
$$

Here, $I_{t}$ is the cumulative infiltration amount at time t, $\mathrm{cm} ; t$ is the infiltration time, min; $K$ is the empirical infiltration coefficient, and its physical meaning is the cumulative amount of infiltration at the end of the first period after the infiltration began. It is also numerically equal to the average infiltration rate of the soil in the first unit period; $\alpha$ is the empirical infiltration index, which reflects the decay rate of the soil infiltration capacity. In the initial stage of infiltration, the parameter $\mathrm{K}$ plays a leading role. As the infiltration process continues, the parameter $\alpha$ becomes the main factor affecting the rate of infiltration.

The Philip model formula is:

$$
I_{t}=S \cdot t^{0.5}+A \cdot t
$$

Here, $S$ is the infiltration rate in $\mathrm{cm} / \mathrm{min}^{0.5} ; A$ is the steady infiltration rate (usually less than the saturated hydraulic conductivity), also in $\mathrm{cm} / \mathrm{min}$.

\section{Results}

\section{The infiltration rate changes over time}

The infiltration rate is defined as the amount of water permeating into a unit of soil per unit area through the surface. Figure 2 reflects the infiltration rate of different soils of different weights in the gravel area over time. The variation of soil infiltration rate over time among soils of different textures and bulk densities shows a rapid decrease followed by stabilization. For the two texture soils, the infiltration rate showed a rapid decrease after $5 \mathrm{~min}$ of infiltration, mainly due to a decrease in the absolute value of the matric potential and the rapid decrease of the soil negative pressure. After 10 min of 
infiltration, the soil matric potential gradient begins to decrease slowly, finally approaching zero. The soil infiltration rate is generally stable, but the time required to reach stable infiltration of different soils with different textures differ. The Lou soil reached a stable infiltration state after $20 \mathrm{~min}$, while the Yellow-brown soil gradually reached stable infiltration after $40 \mathrm{~min}$. During the infiltration process of both soils, the larger the bulk density, the smaller the infiltration rate. The curve of the late infiltration is close to a horizontal straight line, indicating that the influence of soil bulk density on the infiltration rate decreases gradually over time.

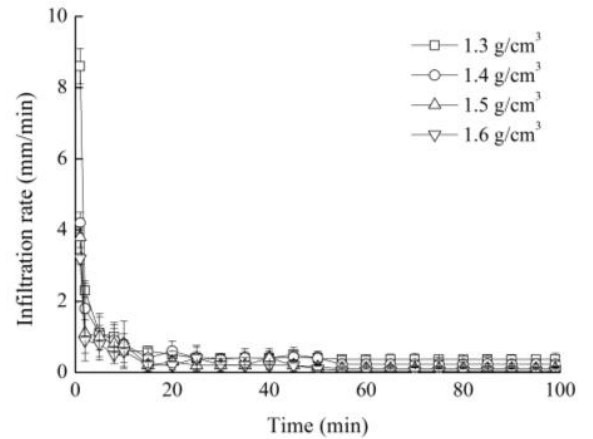

(a) Lou soil

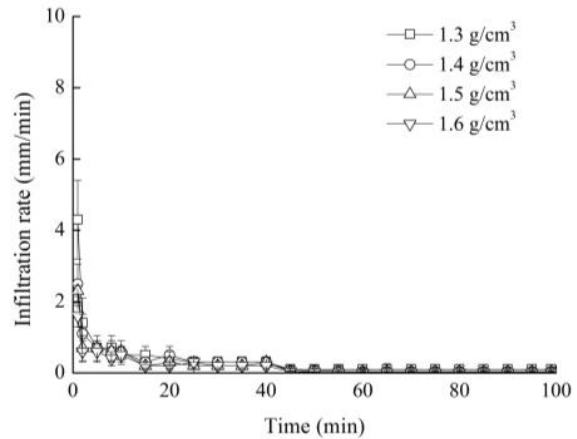

(b) Yellow-brown soil

Figure 2. Infiltration rate over time

Taken together, our soil infiltration test data suggest that soil bulk density has a significant effect on the stable infiltration rate. The stable infiltration rate in turn characterizes the infiltration capacity of the soil infiltration stage. Figure 3 shows the relationship between the soil bulk density and the stable infiltration rate of two different textures, and shows that the bulk density of Lou soil increased from $1.3 \mathrm{~g} / \mathrm{cm}^{3}$ to $1.6 \mathrm{~g} / \mathrm{cm}^{3}$, and the steady infiltration rate decreased from $0.365 \mathrm{~mm} / \mathrm{min}$ to $0.051 \mathrm{~mm} / \mathrm{min}$. In contrast, the bulk density of Yellow-brown soil increased from $1.3 \mathrm{~g} / \mathrm{cm}^{3}$ to $1.6 \mathrm{~g} / \mathrm{cm}^{3}$, and the steady infiltration rate declined from $0.065 \mathrm{~mm} / \mathrm{min}$ to $0.012 \mathrm{~mm} / \mathrm{min}$. At the same bulk density, the stable infiltration rate of Yellow-brown soil is less than that of Lou soil, and the decrease in the soil infiltration rate in Lou soil is greater than the corresponding decrease in Yellow-brown soil. We also found that the soil infiltration rate and bulk density showed a highly significant log-negative correlation (equation shown in Fig. 3). These results showed that the stable infiltration rate of cover soils above gravel was greatly affected by soil bulk density. The steady infiltration rates of the two types of test soils decreased with increasing bulk density. Moreover, both soils showed nearly linear logarithmic relationships. However, the shape of this linear relationship in Lou soil had a relatively steep slope, while Yellowbrown soil showed a relatively flat linear relationship.

\section{Influence of soil bulk density on cumulative infiltration}

The cumulative infiltration amount is defined as the total amount of water infiltrated into the soil through the surface per unit area. Analyses of cumulative infiltration in different soil types under different soil weights over 100 min is shown in Figure 4. These results show that the cumulative infiltration of soils with different bulk density increases over time. At the same time, the larger the bulk density, the smaller the 
cumulative infiltration. We found a significant linear negative correlation between permeability and bulk density $\left(\mathrm{R}^{2}>0.95\right)$, and the relationship between bulk density and cumulative infiltration is shown in Figure 5. In this figure we see that when the bulk density increased from $1.3 \mathrm{~g} / \mathrm{cm}^{3}$ to $1.6 \mathrm{~g} / \mathrm{cm}^{3}$, the cumulative infiltration decreased from $54.6 \mathrm{~mm}$ to $20.3 \mathrm{~mm}$. Moreover, we also see that when the bulk density of Yellow-brown soil increased from $1.3 \mathrm{~g} / \mathrm{cm}^{3}$ to $1.6 \mathrm{~g} / \mathrm{cm}^{3}$, the cumulative infiltration decreased from $29.1 \mathrm{~mm}$ to $16.5 \mathrm{~mm}$. The infiltration amount of the two soils was significantly different at $40 \mathrm{~min}$. The process from the initial state to the final stable infiltration of Lou soil was relatively smooth, and the Yellow-brown soil showed an obvious turning after $40 \mathrm{~min}$. This may be due to the differences in soil texture of the two soils.

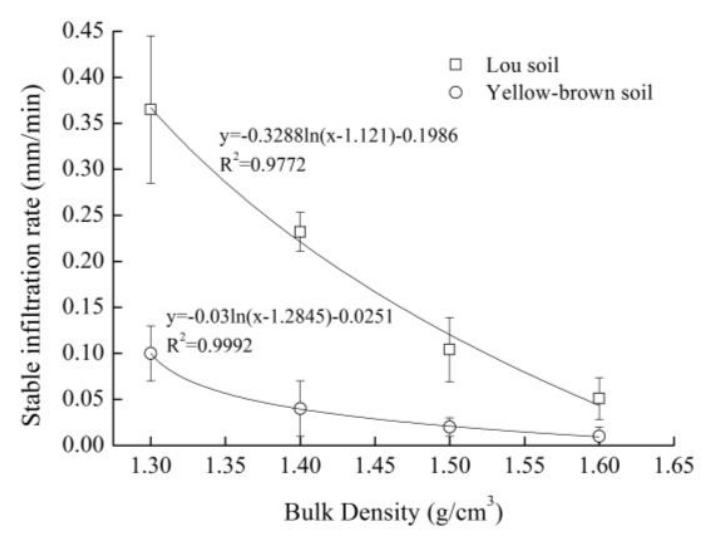

Figure 3. The relationship between stable infiltration rate and soil bulk density

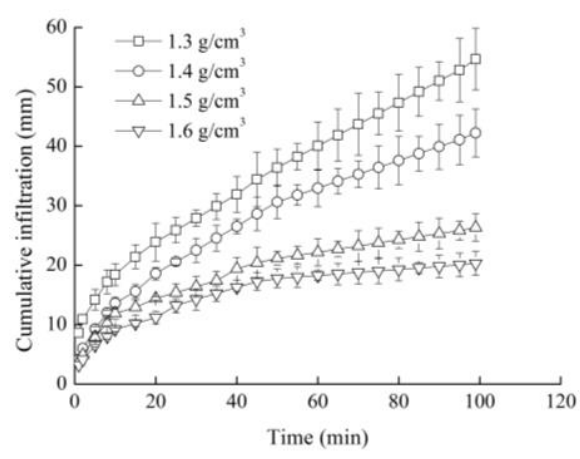

(a) Lou soil

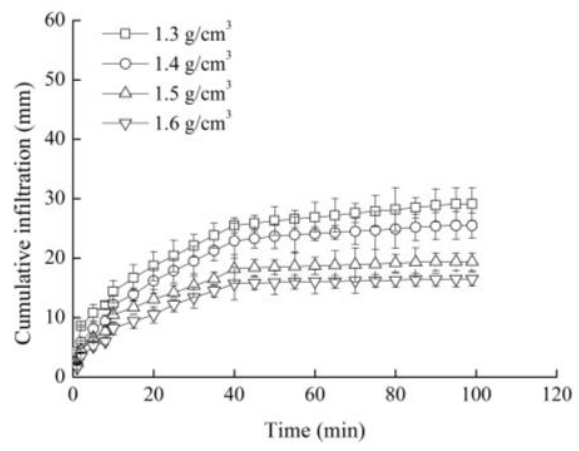

(b) Yellow-brown soil

Figure 4. Cumulative infiltration over time

\section{Infiltration model for soils with different textures and bulk densities}

To further study the influence of covering soil bulk density on soil water infiltration in gravel areas, we used Kostiakov (Eq. 1) and Philip models (Eq. 2) to simulate soil water infiltration in gravel soil. The results of these simulations for both Lou and Yellow-brown soils are shown in Tables 2-4. Lou soil can be better fitted with Kostiakov model. However, fitting of Yellow-brown soil revealed that the infiltration process slowed significantly after $40 \mathrm{~min}$. Neither model simulated Yellow-brown soil well over then 100 min study period, so we then performed model segmentation: the 
Kostiakov and Philip models were used for the first $40 \mathrm{~min}$, then another linear model was fitted after the turning. It can be seen from Tables 2 and 3 that the Kostiakov model effectively simulates the results of the whole infiltration process of the Lou soil as well as the first $40 \mathrm{~min}$ of the Yellow-brown soil infiltration (i.e. $\mathrm{R}^{2}>0.98$ ), while the overall simulation results of the Philip model are poor. Thus the Philip model has poor applicability when describing soil water infiltration processes the gravel cover soil. The infiltration process of the Yellow-brown soil after the first $40 \mathrm{~min}$ can be better described by a linear equation $\left(\mathrm{R}^{2}>0.95\right)$. Taken together, our data support the use of the Kostiakov model for further analysis of water infiltration in the two soils.

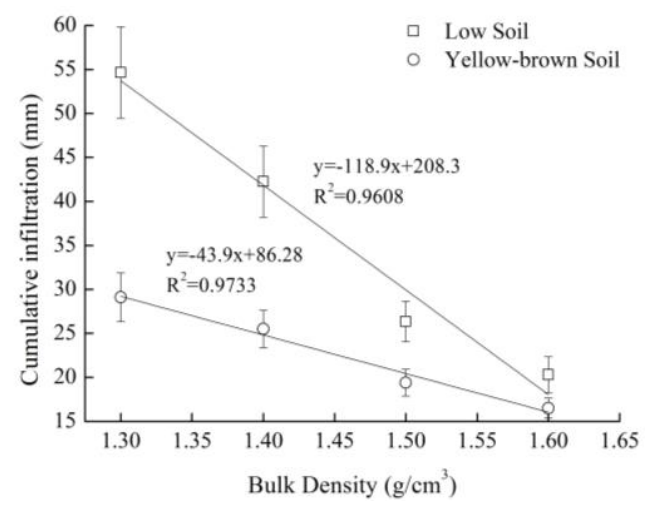

Figure 5. The relationship between cumulative infiltration and bulk density of test soil

The $\mathrm{K}$ value indicates the cumulative infiltration rate at the end of the first period after the start of soil infiltration-i.e. the initial infiltration rate, which is mainly affected by the soil structure. For samples of the same soil texture type, the main factors affecting the $\mathrm{K}$ value are the pore distribution characteristics of the soil, which are mainly determined by soil bulk density. In general, the larger the bulk density, the smaller the porosity and the denser the soil. It can be seen from Tables 2 and 3 that as the bulk density increases, the $\mathrm{K}$ value decreases gradually. When the bulk density of Lou Soil increased from $1.3 \mathrm{~g} / \mathrm{cm}^{3}$ to $1.6 \mathrm{~g} / \mathrm{cm}^{3}$, the $\mathrm{K}$ value decreased from 5.776 to 3.953. In Yellow-brown soil the $\mathrm{K}$ value decreased from 5.387 to 2.168 in response to the same change, and the $\mathrm{K}$ values of the Yellow-brown soil was consistently lower than the $\mathrm{K}$ values of Lou soil. In the initial stage of water infiltration, the macropores in the surface soil are first filled with water by the action of the soil matric potential. This water is affected by the gravitational and the matric potentials, and eventually migrates deeper in the soil, given small bulk density and large pores. With increasing bulk density, the soil macropores decrease and the initial infiltration capacity decreases. Therefore, the $\mathrm{K}$ value generally decreases as volume density increases.

The empirical infiltration index $\alpha$ reflects the decay rate of the soil infiltration capacity. The larger the $\alpha$ value, the faster the infiltration capacity decays. Tables 2 and 3 show that the Lou and Yellow-brown soils have opposite relationships between bulk density and the $\alpha$ value. Increasing the bulk density of Lou soil results in an increase in the $\alpha$ value - e.g. when the bulk density of Lou Soil increased from $1.3 \mathrm{~g} / \mathrm{cm}^{3}$ to $1.6 \mathrm{~g} / \mathrm{cm}^{3}$, the $\alpha$ value increased from 0.521 to 0.634 . In contrast, increasing the bulk density of Yellow-brown soil resulting in a decrease in the $\alpha$ value-e.g. when the bulk density of Yellow-brown soil increased from $1.3 \mathrm{~g} / \mathrm{cm}^{3}$ to $1.6 \mathrm{~g} / \mathrm{cm}^{3}$, the $\alpha$ value decreased from 0.583 to 0.464 . For Lou soil, the larger the bulk density of the 
overburden, the faster the soil water infiltration capacity decays with time. Moreover, the smaller the bulk density of the soil, the slower the decay rate of soil water infiltration capacity with time, resulting in the accumulation of water. This results in a curve that becomes more horizontal as bulk density increases. A change in bulk density causes a large change in the $\alpha$ value, the smaller the soil bulk density and the larger the pores, the better the internal connectivity of the soil, which facilitates moisture penetration. Large pores also result in the discharge of air, thereby reducing the influence of air resistance on the infiltration process. Soil structures with larger bulk densities have less macroporous content, and the pores of such soils are enriched by infill of soil particles, thereby reducing internal connectivity. When soil moisture enters the pores, it often forms due to the surface tension of water. Smaller bubbles cause reduced gas discharge and increase the resistance to soil moisture infiltration. Gas resistance can cause a rapid decay in infiltration capacity. Therefore, the $\alpha$ value increases with increasing bulk density.

Table 2. Fitting results of infiltration model of Lou Soil

\begin{tabular}{c|c|c|c|c|c|c|c}
\hline \multirow{2}{*}{$\begin{array}{c}\text { Bulk } \\
\text { density } \\
\left(\mathbf{g} / \mathbf{c m}^{\mathbf{3}}\right)\end{array}$} & \multicolumn{4}{|c|}{ Kostiakov model } & \multicolumn{3}{|c}{ Philip model } \\
\cline { 2 - 7 } & $\mathbf{K}$ & $\boldsymbol{\alpha}$ & $\mathbf{K} / \boldsymbol{\alpha}$ & $\mathbf{R}^{\mathbf{2}}$ & $\mathbf{S}$ & $\mathbf{A}$ & $\mathbf{R}^{\mathbf{2}}$ \\
\hline 1.3 & 5.776 & 0.521 & 11.086 & 0.988 & 5.294 & $6.64 \mathrm{E}-4$ & 0.987 \\
1.4 & 4.116 & 0.494 & 8.332 & 0.999 & 4.157 & 0.0078 & 0.999 \\
1.5 & 4.505 & 0.613 & 7.349 & 0.995 & 3.591 & $3.21 \mathrm{E}-7$ & 0.329 \\
1.6 & 3.953 & 0.634 & 6.235 & 0.981 & 3.274 & $1.02 \mathrm{E}-9$ & 0.754 \\
\hline
\end{tabular}

Table 3. Descriptive statistics of an infiltration model of yellow-brown soil before the transition

\begin{tabular}{c|c|c|c|c|c|c|c}
\hline \multirow{2}{*}{$\begin{array}{c}\text { Bulk density } \\
\left(\mathbf{g} / \mathbf{c m}^{\mathbf{3}}\right)\end{array}$} & \multicolumn{4}{|c|}{ Kostiakov model } & \multicolumn{3}{c}{ Philip model } \\
\cline { 2 - 8 } & $\mathbf{K}$ & $\boldsymbol{\alpha}$ & $\mathbf{K} / \boldsymbol{\alpha}$ & $\mathbf{R}^{\mathbf{2}}$ & $\mathbf{S}$ & $\mathbf{A}$ & $\mathbf{R}^{\mathbf{2}}$ \\
\hline 1.3 & 5.387 & 0.583 & 9.249 & 0.990 & 4.893 & 0 & 0.711 \\
1.4 & 3.566 & 0.497 & 7.174 & 0.992 & 3.590 & 0.00195 & 0.992 \\
1.5 & 3.122 & 0.526 & 5.942 & 0.987 & 3.081 & 0 & 0.954 \\
1.6 & 2.168 & 0.464 & 4.670 & 0.992 & 2.224 & 0.04050 & 0.992 \\
\hline
\end{tabular}

Table 4. Descriptive statistics of a linear infiltration model of yellow-brown soil after the transition

\begin{tabular}{c|c|c|c}
\hline \multirow{2}{*}{$\begin{array}{c}\text { Bulk density } \\
\left(\mathbf{g} / \mathbf{c m}^{\mathbf{3}}\right)\end{array}$} & $\mathbf{3}$ & $\mathbf{b}$ & $\mathbf{R}^{\mathbf{2}}=\mathbf{a} \cdot \mathbf{t}+\mathbf{b}$ \\
\cline { 2 - 4 } & 0.06454 & 22.13329 & 0.99504 \\
1.3 & 0.04429 & 20.98801 & 0.98907 \\
1.4 & 0.02237 & 16.98222 & 0.98767 \\
1.5 & 0.01384 & 15.17097 & 0.96204 \\
\hline
\end{tabular}


Yellow-brown soil behaves differently-soil samples of the same texture will show large differences in $\alpha$ value from small changes in bulk density. The $\alpha$ value of Yellowbrown soil showed a slight decrease with increasing bulk density. This is mainly due to the relatively high content of clay in the soil and the low number of macropores present. The initial infiltration rate is small, and the larger the bulk density, the smaller the degree of attenuation of the infiltration velocity; therefore the relationship between the bulk density and the $\alpha$ value differs.

The $\mathrm{K} / \alpha$ ratio reflects the whole infiltration process. On the whole, larger $\mathrm{K} / \alpha$ ratios indicate stronger infiltration ability. In our data, we found that $\mathrm{K} / \alpha$ decreased with increasing bulk density in both soils. At the same time, we also found that there was a significant inflection point in cumulative infiltration of Yellow-brown soil. The variation in cumulative infiltration over time after turning can be described linearly, and the linear slope decreases with increasing bulk density (Table 4).

\section{Effect on soil water content and water storage capacity}

The redistribution of soil moisture affects the distribution of water content in all layers of soil, and therefore directly affects the availability of soil moisture for plants (Liang et al., 2015). Figures 6 and 7 show distribution curves of the water content of each layer of soil at the end of the infiltration test, as well as the degree of redistribution at $24 \mathrm{~h}, 72 \mathrm{~h}$, and $240 \mathrm{~h}$ for different soil bulk densities of Lou and Yellow-brown soil. At the end of infiltration, both soils showed the same pattern: the greater the soil bulk density, the smaller the water content at the same soil layer height. This is likely due to greater soil bulk density resulting in weaker water holding capacity. At the bottom of the soil layer, due to the gravel having poor water holding capacity and strong permeability, the soil moisture in contact with the gravel layer moves downward, and the water content is the lowest. Water redistribution, under the joint action of matric and gravity potentials, involves soil moisture migrating to the vertical deep and dry soil. Moreover, we found that the soil bulk density became smaller as the redistribution period progressed. This is because as water migrates downward during redistribution, the gravity potential becomes more influential, causing the soil moisture content to increase with soil depth, thus decreasing bulk density. For instance, in our Yellowbrown soil trials the moisture content of the lower soil layer was low at all bulk density values, and the redistribution process was slower than it was in Lou soil.

Following water infiltration, changing soil water storage capacity varies in response to the redistribution of soil moisture among soil layers, as shown in Figure 8. The Bulk density of the soil covering the gravel has a significant effect on the water storage capacity of soil layers up to $30 \mathrm{~cm}$ below the surface. At early stages of water redistribution, the smaller the bulk density, the greater the water storage capacity. However, as time progresses, soil types with small bulk density have a high water capacity but lose water quickly. In contrast, soils with slower redistribution phases generally have better water retention. At a bulk density of $1.3 \mathrm{~g} / \mathrm{cm}^{3}$, water storage capacity of Lou soil decreased from an initial volume of $12.2 \mathrm{~cm}$ to a volume of $5.8 \mathrm{~cm}$ $10 \mathrm{~d}$ after infiltration. When the bulk density was $1.6 \mathrm{~g} / \mathrm{cm}^{3}$, the water storage capacity was $9.6 \mathrm{~cm}$ at initial infiltration, and was reduced by $17.7 \%$ (i.e. to $7.9 \mathrm{~cm}$ ) after $10 \mathrm{~d}$. This was different in Yellow-brown soil. At a bulk density of $1.3 \mathrm{~g} / \mathrm{cm}^{3}$, its water storage capacity declined from $11.8 \mathrm{~cm}$ to $6.4 \mathrm{~cm}(45.8 \%)$ over the same time period. Moreover, at a bulk density of $1.6 \mathrm{~g} / \mathrm{cm}^{3}$, the soil water storage declined from $11.0 \mathrm{~cm}$ to $9.7 \mathrm{~cm}$, a reduction of only $11.8 \%$. 


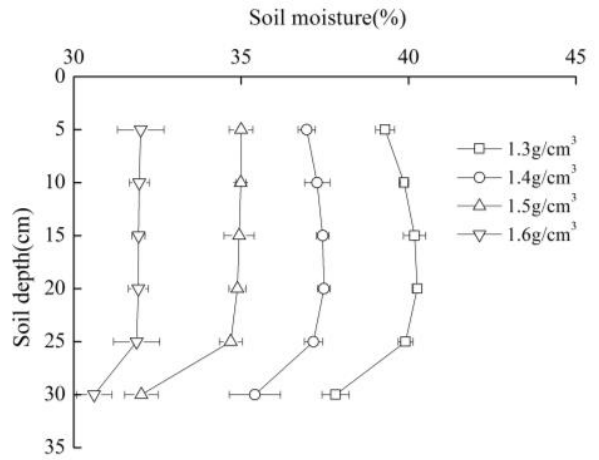

(a) After infiltration

Soil moisture(\%)

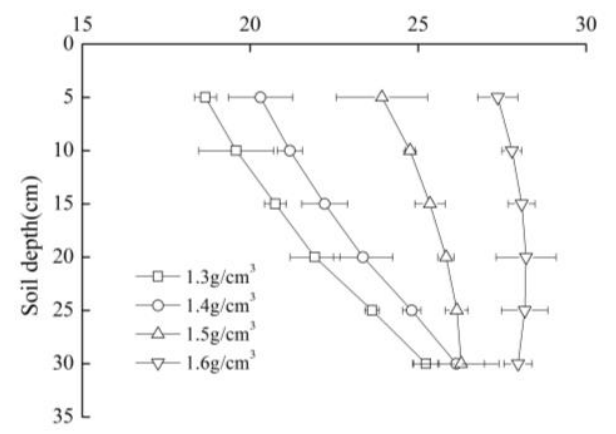

(c) Redistribution after $72 \mathrm{~h}$

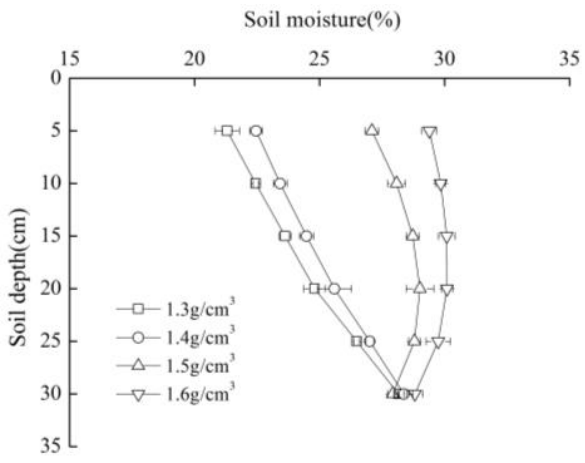

(b) Redistribution after $24 \mathrm{~h}$ Soil moisture(\%)

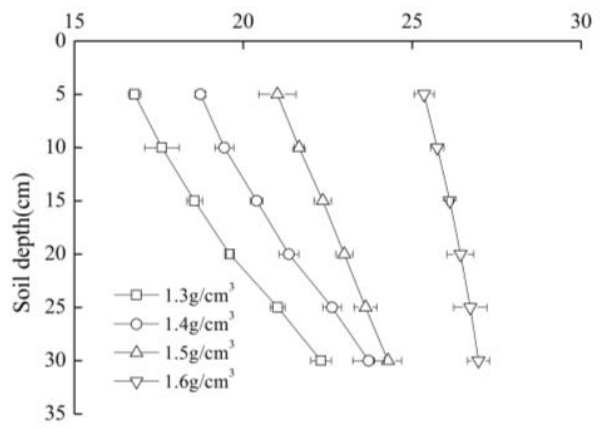

(d) Redistribution after $240 \mathrm{~h}$

Figure 6. Water content distribution of each soil layer under different soil bulk densities of Lou soil

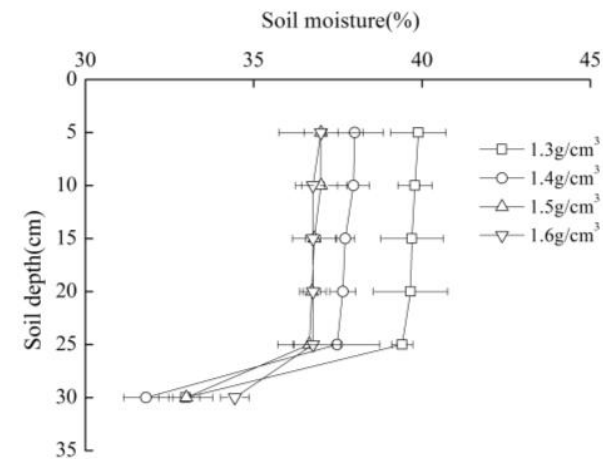

(a) After infiltration

Soil moisture(\%)

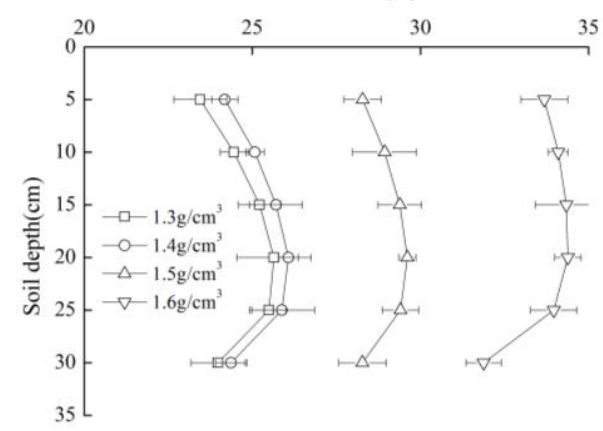

(c) Redistribution after $72 \mathrm{~h}$

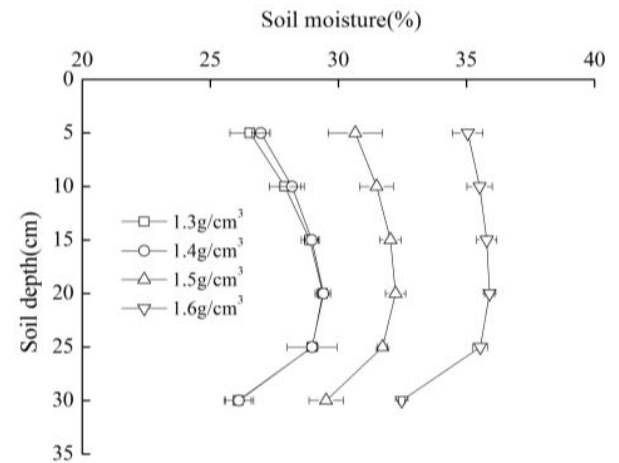

(b) Redistribution after $24 \mathrm{~h}$

Soil moisture(\%)

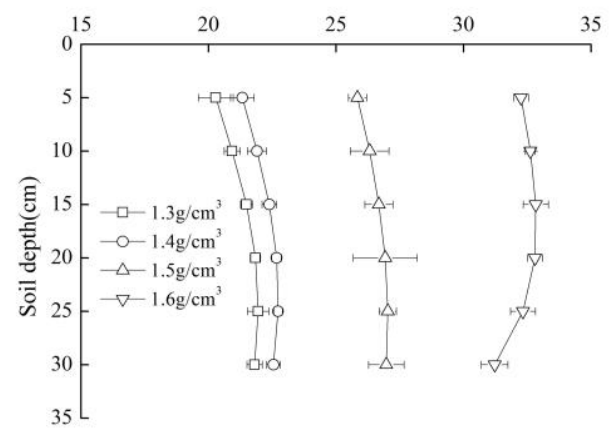

(d) Redistribution after $240 \mathrm{~h}$

Figure 7. Distribution of water content in each soil layer under different soil bulk densities of Yellow-brown soil 


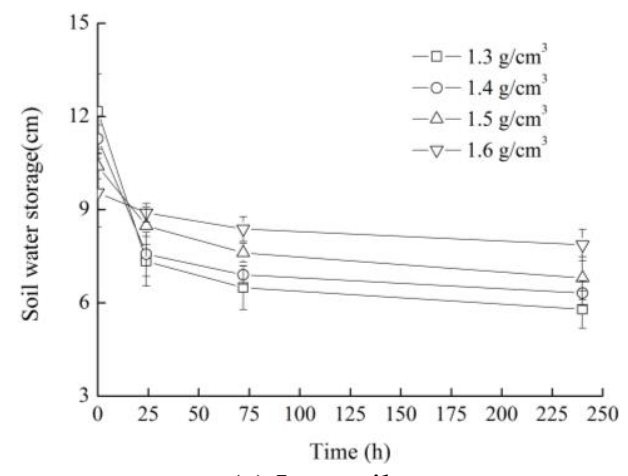

(a) Lou soil

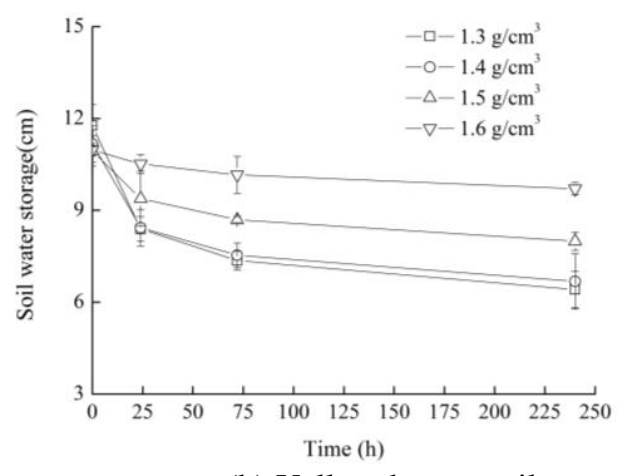

(b) Yellow-brown soil

Figure 8. The effect of bulk density on soil water storage capacity

\section{Discussion}

The infiltration rate reflects the infiltration performance of the soil. When the gravel is covered with soil, it is especially important to consider the soil infiltration performance of the resulting soil mixture. The bulk density structure, which strongly affects the water storage capacity and drainage capacity of the soil, can cause crops to be flooded when infiltration capacity is too low to discharge accumulated water quickly. However, if the infiltration capacity is too high, it is difficult to retain water in the soil. The effect of bulk density on water infiltration capacity is determined by the number of macropores present. According to Darcy's seepage law of unsaturated soil, the infiltration of soil moisture is determined by soil hydraulic conductivity and soil water potential gradient, while soil hydraulic conductivity is mainly determined by soil texture, bulk density, structure, moisture content, and matric potential (Wang et al., 2017). The initial stage of infiltration is mainly affected by the soil matric potential. Due to the low initial soil water content, the soil negative pressure is large and the matric potential gradient at the interface between the accumulated water and the soil column is also large, resulting in a higher initial infiltration rate. The infiltration process is gradually influenced by the gravity potential, and the infiltration rate decreases rapidly. Soil texture and bulk density affect the hydraulic conductivity of soil by affecting the size and distribution of soil pores, especially macropores and conductive pores.

In this study, we examined differences in soil moisture infiltration among different topsoil cover treatments for gravel-mulched areas. Our findings were similar to those of Kang et al. (2016), who confirmed that both the infiltration rate and cumulative infiltration decreased with increasing soil bulk density. The cumulative infiltration amount and its relationship over time is important to analyse the effect of rainfall and irrigation after soil covering in gravel-mulched areas. Soil bulk density had a great influence on cumulative infiltration during the infiltration process, and the cumulative infiltration was negatively correlated with soil bulk density. The infiltration capacity depends on the distribution of macropores in soil, because water migration channels in soil mainly depend on the presence of conductive pores and macropores (Fu et al., 2008). Soil bulk density is determined by the size and quantity of pores in the soil and the degree of soil compaction. The smaller the soil bulk density, the higher the pore content and the stronger the infiltration capacity and the moisture flux (Zhao et al., 2008). At the same time, we also found a negative linear correlation between the stable 
infiltration rate and the logarithm of soil bulk density. This finding is consistent with those of Li et al. (2009b). Water infiltration into soil layers on a gravel base is well described by the widely-used Kostiakov model. However, we also found that the sticky soil texture of Yellow-brown soil has a turning point late in the process of infiltration, which agrees with the findings of Song et al. (2013) on their studies of water retention in water-repellent soils. Finally, we found that as infiltration progresses, the rate of infiltration rate changes slowly before stabilizing. Our results showed that after infiltration, the redistribution of soil moisture proceeded in a way similar to that described by Zeng. The major difference between the findings of that study and our results is that here the middle and lower soil layers were composed of gravel, and the loss of soil moisture at the end of the redistribution process was relatively small.

\section{Conclusions}

In this study, indoor simulated soil column tests were used to examine the relationship between soil traits and infiltration performance. We found that covering soil bulk density and texture strongly influenced infiltration and soil moisture levels present in different soil strata in gravel-mulched areas. We also note three key findings from this study.

First, when gravel is covered in soil, the importance of soil weight and textures is larger. This is because the soil porosity of the topsoil layer is smaller than the gravel underneath, reducing the connectivity between soil pores. This results in a lower infiltration rate. Moreover, the stable infiltration rate has a logarithmic negative correlation with soil bulk density. We also found that at the same bulk density, the stable infiltration rate of Yellow-brown soil is lower than that of Lou soil, and the decrease in the soil infiltration rate caused by the increase of bulk density in Lou soil was much greater than the corresponding increase in Yellow-brown soil.

Second, we found that the cumulative infiltration of soil at all bulk densities increases with time. At the same time, the larger the bulk density, the smaller the cumulative infiltration. After $100 \mathrm{~min}$ of infiltration, we found a significant linear negative correlation between the degree of infiltration and soil bulk density $\left(R^{2}>0.95\right)$. Moreover, we used a Kostiakov model to characterize the first 100 min of infiltration in Lou soil and the first $40 \mathrm{~min}$ of infiltration in Yellow-brown soil. The Yellow-brown soil showed obvious turning after 40 min of infiltration, and the infiltration process can then be described by a linear equation.

Finally, at the initial moment of the end of infiltration, the soil moisture content of the bottommost layer of soil (30 $\mathrm{cm}$ below the surface) was small, even where the soil water content at other depths was close to saturation. Moreover, 10 days after the end of infiltration, the soil moisture of greater bulk density in the same soil layer is larger than it was of smaller bulk density. After infiltration, redistribution causes the soil water content to increase with increasing soil depth, although the redistribution process in Yellow-brown soil lags behind that of Lou soil. In the initial stage of soil water redistribution, smaller bulk density was linked to greater water storage capacity in the soil. As time progresses, soils with smaller bulk densities lose water faster.

Considering that the gravel-mulched land is used for crop planting after covering soils, the soil should stabilize and retain water, we suggest that the soil bulk density should be no less than $1.5 \mathrm{~g} / \mathrm{cm}^{3}$ when Lou soil was chosen to cover on gravel-mulched land, and not less than $1.4 \mathrm{~g} / \mathrm{cm}^{3}$ for Yellow-brown soil. 
In order to further clarify the law of water infiltration after covering soil in the gravel-mulched areas, the effect of gravel particle size on water infiltration and the migration of nutrients may be studied with undisturbed soil in future researches.

Acknowledgements. This study was funded by the Fundamental Research Funds for the Central Universities, CHD (No.300102279502); we also acknowledge TopEdit LLC for linguistic editing and proofreading during the preparation of this manuscript.

\section{REFERENCES}

[1] Cerdà, A. (2001): Effects of rock fragment cover on soil infiltration, interrill runoff and erosion. - European Journal of Soil Science 52(1): 59-68.

[2] Chen, L., Huang, Z., Gong, J., Fu, B., Huang, Y. (2007): The effect of land cover/vegetation on soil water dynamic in the hilly area of the Loess Plateau, China. Catena 70(2): 0-208.

[3] Fu, B., Wang, Y. K., Zhu, B., Wang, D. J., Wang, X. T., Wang, Y. Q., Ren, Y. (2008): Experimental study on rainfall infiltration in sloping farmland of purple soil. Transactions of the Chinese Society of Agricultural Engineering 24(7): 39-43.

[4] Hillel, D. (1998): Environmental Soil Physics. - Academic Press, New York.

[5] Kang, J. L., Yang, J., Liu, Y. J., Tu, A. G. (2016): Impacts of soil initial water content and bulk density on infiltration law of red soil. - Journal of Soil and Water Conservation 30(1): 122-126.

[6] Li, Z. M., Zhou, Q., Wang, H., Lu, X. (2009a): Influence of bulk density on the characteristic of water solute transport in red soil. - Journal of Soil and Water Conservation 23(5): 101-103.

[7] Li, Z., Wu, P. T., Feng, H., Zhao, X. N., Huang, J., Zhuang, W. H. (2009b): Simulated experiment on effect of soil bulk density on soil infiltration capacity. - Transactions of the Chinese Society of Agricultural Engineering 25(6): 40-45.

[8] Liang, W. L., Kosugi, K., Mizuyama, T. (2015): Soil water redistribution processes around a tree on a hillslope: the effect of stemflow on the drying process. - Ecohydrology 8(8): 1381-1395.

[9] Mandal, U. K., Rao, K. V., Mishra, P. K., Vittal, K. P. R., Sharma, K. L. (2005): Soil infiltration, runoff and sediment yield from a shallow soil with varied stone cover and intensity of rain. - European Journal of Soil Science 56(4): 435-443.

[10] Mehuys, G. R., Stolzy, L. H., Letey, J. (1975): Effect of stones on the hydraulic conductivity of relatively dry desert soil. - Soil Science Society of America Journal 39(1): 37-42.

[11] Novák, V., Kňava, K. (2012): The influence of stoniness and canopy properties on soil water content distribution: simulation of water movement in forest stony soil. - European Journal of Forest Research 131(6): 1727-1735.

[12] She, D. L., Liu, Y. Y., Liu, D. D., Xu, C. L., Qu, X., Chen, Y. L., Deng, L. Y., Yu, S. E. (2012): Study on impact of soil bulk density on infiltration properties of silt soil in coastal reclamation regions. - Research of Agricultural Modernization 33(6): 749-752+761.

[13] Song, H. Y., Li, Y., He, C. S. (2013): Infiltration models for different textures of waterrepellent soils. - Journal of Drainage and Irrigation Machinery Engineering 31(7): 629635.

[14] Sun, Z. H., Zhang, Y., Wang, H. Y. (2017): Effect of soil bulk density on soil infiltration in land or organic reconstruction on based on HYDRUS-1D model. - Land Develop Land Development and Engineering Research 2(7): 20-27.

[15] Tejedor, M., Neris, J., Jiménez, C. (2013): Soil properties controlling infiltration in volcanic soils. - Egu General Assembly 15(1): 202-212. 
[16] Wang, X. Y., Cai, C. F., Li, H., Xie, D. T. (2017): Influence of rock fragments on bulk density and pore characteristics of purple soil in Three-Gorge Reservoir area. - Acta Pedologica Sinica 54(2): 379-386.

[17] Yi, L., Zhang, Z. X., Wang, X., Liu, B., Zuo, L. J., Zhao, X. L., Wang, J. (2013): Spatialtemporal change of major reserve resources of cultivated land in China in recent 30 years.

- Transactions of the Chinese Society of Agricultural Engineering 29(6): 1-12.

[18] Zavala, L. M., Jordán, A., Bellinfante, N., Gil, J. (2009): Relationships between rock fragment cover and soil hydrological response in a Mediterranean environment 2010. Soil Science and Plant Nutrition 56(1): 95-104.

[19] Zeng, J., Fei, L. J., Pei, Q. B. (2017): Influence of soil bulk density on soil water infiltration characteristics in water vertical movement for red loams. - Journal of Drainage and Irrigation Machinery Engineering 35(12): 1081-1087.

[20] Zhang, Y., Li, Z. B., Dong, Q. G. (2017): Effects of covering soil thickness of bare rock gravel land on soil moisture. - Yangtze River 48(24): 52-55.

[21] Zhang, Y., Li, Z. B., Dong, Q. G., Yuan, S. L. (2018): Experimental study on influence of overburden thickness on soil particle transport process in bare rock gravel land. - Journal of Soil and Water Conservation 32(2): 87-91+103.

[22] Zhao, Y. G., Zhao, S. W., Cao, L. H., Liang, X. F. (2008): Soil structural characteristics and its effect on infiltration on abandoned lands in semi-arid typical grassland areas. Transactions of the Chinese Society of Agricultural Engineering 24(6): 14-20.

[23] Zhou, B. B., Shao, M. A., Shao, H. B. (2009): Effects of rock fragments on water movement and solute transport in a Loess Plateau soil. - Comptes Rendus Geoscience 341(6): 462-472. 